\title{
Idiopathic intracranial hypertension: ongoing clinical challenges and future prospects
}

This article was published in the following Dove Press journal:

Journal of Pain Research

19 February 2016

Number of times this article has been viewed

\author{
Parunyou Julayanont' \\ Amputch Karukote ${ }^{2}$ \\ Doungporn Ruthirago' \\ Deepa Panikkath ${ }^{3}$ \\ Ragesh Panikkath ${ }^{3}$ \\ 'Department of Neurology, Texas \\ Tech University Health Science \\ Center, Lubbock, TX, USA; ${ }^{2}$ Faculty \\ of Medicine Ramathibodi Hospital, \\ Mahidol University, Bangkok, Thailand; \\ ${ }^{3}$ Department of Internal Medicine, \\ Texas Tech University Health Science \\ Center, Lubbock, TX, USA
}

Correspondence: Parunyou Julayanont Department of Neurology, Texas Tech University Health Science Center, 360I 4th Street, STOP 832I, Lubbock, TX 79430-832I, USA

$\mathrm{Tel}+\mathrm{I} 8067433832$

Fax + I 8067435687

Email p.julayanont@ttuhsc.edu; prun_u@hotmail.com

\begin{abstract}
Idiopathic intracranial hypertension (IIH) is an uncommon disorder characterized by increased intracranial pressure without radiological or laboratory evidence of intracranial pathology except empty sella turcica, optic nerve sheath with filled out cerebrospinal fluid spaces, and smooth-walled nonflow-related venous sinus stenosis or collapse. This condition typically affects obese women. The incidence of IIH is increasing with the rising prevalence of obesity. Persistent headache is the most common symptom. Visual impairment is a serious complication that may not be recognized by the patients. This paper reviews clinical manifestations, diagnostic challenges, and current treatments of IIH in adults. Various imaging modalities have been studied on their validity for detection of IIH and papilledema. This review also includes new studies on medical, surgical, and interventional management of this condition. Acetazolamide and topiramate are the only two medications that have been studied in randomized controlled trials about their efficacy in treatment of IIH. In patients who have severe visual impairment or progressive visual deterioration despite medical management, surgical or interventional treatment may be considered. The efficacy and complications of cerebrospinal fluid diversion, optic nerve sheath fenestration, and endovascular venous stenting reported in the last 3 decades have been summarized in this review. Finally, the prospective aspects of biomarkers and treatments are proposed for future research.
\end{abstract}

Keywords: acetazolamide, cerebrospinal fluid shunts, endovascular stenting, optic nerve sheath fenestration, pseudotumor cerebri

\section{Introduction}

Idiopathic intracranial hypertension (IIH) is an uncommon disorder of increased intracranial pressure (ICP) without radiological and laboratory evidence of intracranial pathology. Even though the clinical presentations of this condition are well-characterized, the pathogenesis remains unclear. Although obese women of childbearing age are typically affected, IIH can affect patients of any age or sex. Incidence of IIH largely varies from 0.03 to $2.36 / 100,000 /$ year in total population. ${ }^{1-9}$ As female sex and obesity are the risk factors for IIH, higher incidence was reported in female population $(0.65-4.65 / 100,000 / \text { year })^{3-8}$ and in obese women (2.7-19.3/100,000/year). ${ }^{4,5}$ In the last decade, its incidence has been rising due to the globally increasing prevalence of obesity. ${ }^{9}$ Chronic headache and visual impairment are the main presentation symproms of IIH. Quality of life is also affected by $\mathrm{IIH}$, even in patients with mild visual impairement. ${ }^{10}$

\section{Clinical manifestations}

Headache is the most common symptom of IIH present in $80 \%-90 \%$ of patients. ${ }^{11,12}$ Headache is typically a bilateral frontal or retro-orbital throbbing or pressure and may 
be associated with nausea, vomiting, and transient visual obscuration. Patients often give history of worsening of headache in comparison to the headaches that they have experienced in the past. Some patients present with chronic daily headache with 12 days of headache per month on average. ${ }^{12}$ There is no relationship between severity or frequency of headache and ICP. ${ }^{13}$ Sometimes, it is challenging to differentiate the headache associated with IIH from other primary headache syndromes. For example, $41 \%$ of patients with IIH reported premorbid migraine history. ${ }^{12}$ Clinical features of chronic headache in IIH and chronic migraine are very difficult to distinguish. ${ }^{14}$ Medication-overuse headache is another condition that can mimic headache in IIH. Some IIH patients report mild-to-moderate continuous headache that can mimic the headache features in chronic tension-type headache. The diagnostic criteria for headache attributed to IIH proposed by the International Headache Society are shown in Table $1 .{ }^{15}$

IIH can cause transient visual obscurations, loss of visual acuity, visual field defects, and tunnel vision. Transient visual obscuration, which is transient loss or graying out of vision lasting a few seconds, occurs in $68 \%$ of patients

Table I IHS diagnostic criteria for headache attributed to IIH

A. Progressive headache with at least one of the following characteristics and fulfilling criteria $C$ and $D$ :

I. Daily occurrence

2. Diffuse and/or constant (nonpulsating) pain

3. Aggravated by coughing or straining

B. Intracranial hypertension fulfilling the following criteria:

I. Alert patient with neurological examination that either is normal or demonstrates any of the following abnormalities:

- Papilloedema

- Enlarged blind spot

- Visual field defect (progressive if untreated)

- Sixth nerve palsy

2. Increased CSF pressure $\left(>200 \mathrm{~mm} \mathrm{H}_{2} \mathrm{O}\right.$ in the nonobese, $>250 \mathrm{~mm} \mathrm{H}_{2} \mathrm{O}$ in the obese) measured by lumbar puncture in the recumbent position or by epidural or intraventricular pressure monitoring

3. Normal CSF chemistry (low CSF protein is acceptable) and cellularity

4. Intracranial diseases (including venous sinus thrombosis) are ruled out by appropriate investigations

5. No metabolic, toxic, or hormonal causes of intracranial hypertension

C. Headache develops in close temporal relation to increased intracranial pressure

D. Headache improves after withdrawal of CSF to reduce pressure to $120-170 \mathrm{~mm} \mathrm{H}_{2} \mathrm{O}$ and resolves within 72 hours of persistent normalization of intracranial pressure

Abbreviations: IHS, International Headache Society; IIH, idiopathic intracranial hypertension; CSF, cerebrospinal fluid. and is related to papilledema. ${ }^{12}$ The mechanism of transient visual obscuration remains unclear. Ischemia of optic nerve head and downward herniation of the parahippocampal gyrus in the tentorial notch are the proposed mechanisms of this symptom.

Abducens nerve is the most common cranial nerve affected by elevated ICP manifesting in horizontal binocular diplopia. Sixth nerve palsy can be either unilateral or bilateral and is a false localizing sign in this condition.

Intermittent tinnitus has been reported in $52 \%$ of IIH cases. ${ }^{12}$ This may be unilateral or bilateral, often described as a whooshing, wind-like, or a pulsatile noise. Tinnitus is explained by the compressive effect of intracranial hypertension to venous sinuses, resulting in turbulent blood flow. ${ }^{16}$ Low-frequency hearing loss and vertigo can be found in IIH patients. Prolonged interpeak latencies in auditory brainstemevoked response was reported in one-third of patients with IIH that may be caused by compression-stretching of cochlear nerve and brainstem from intracranial hypertension. ${ }^{17}$

It is interesting to mention about the cognitive profile in IIH patients. Although, cognitive function is not routinely evaluated in patients with IIH, multiple domains of cognitive function are impaired in IIH patients, including memory, executive function, visuospatial processing, attention, motor skills, working memory, and processing speed..$^{18-20}$ The most severe deficits were reaction time and processing speed. ${ }^{19}$ Despite significant improvement in headache, cognitive dysfunction may persist even after 3 months of treatment. ${ }^{19}$

Similar to the optic nerve, the olfactory nerve is surrounded by meningeal sheath and cerebrospinal fluid (CSF), which could also be affected by the elevation of ICP. Impaired olfactory function has been recognized in many recent studies as one of the symptoms in IIH patients. ${ }^{21-24}$ There was a report of morphological change of olfactory bulb volume in untreated symptomatic IIH patients. ${ }^{25}$ In addition to the measurement of visual impairment, papilledema, or headache, it is interesting to study the role of olfactory nerve function and morphology in early diagnosis of IIH and as an outcome measurement after treatment of IIH.

\section{Diagnostic challenges Neuroimaging}

Neuroimaging is helpful in excluding other causes of raised intracranial tension like space-occupying lesions. Venous sinus thrombosis can present with severe headache from intracranial hypertension secondary to impairment of CSF reabsorption, which can clinically mimic IIH symptoms. Magnetic resonance imaging (MRI) of the head and orbit with 
intravenous contrast and magnetic resonance venography (MRV) are the modalities of choice to exclude any structural lesions prior to IIH diagnosis. Several radiologic signs are suggestive of IIH; however, none of them are pathognomonic for this condition.

Intracranially, empty or partially empty sella sign and decreased pituitary height are commonly seen in IIH. Sella turcica is a saddle-shaped depression in the sphenoid bone where the pituitary gland is situated. Prolonged intracranial hypertension enlarges bony structure of pituitary fossa with minimal effect on the pituitary size, which contributes to the partial empty appearance of sella turcica in MRI. ${ }^{26,27}$ Herniation of subarachnoid space to the anterior portion of sella turcica diaphragm is the hypothesis of empty or partially empty sella sign in IIH. Enlargement of sella area provided high sensitivity (100\%) and specificity (90\%) in differentiating IIH from normal controls. ${ }^{27}$ The area of the pituitary gland has been reported to be very sensitive (100\%) for detecting posttreatment changes. ${ }^{27}$

Narrowing of trigeminal cave, an arachnoid pouch containing CSF and trigeminal ganglion, is a novel finding reported in $\mathrm{IIH}^{28}$ Apart from effect on sella turcica, bone erosion and remodeling secondary to chronic intracranial hypertension may result in widening of the bony canals of the skull base. Enlargement of the foramen ovale demonstrated high specificity ( $81 \%$ ), but low sensitivity (50\%) in diagnosis of $\mathrm{IIH}^{29}$ The jugular foramen and hypoglossal canal were also reported to be enlarged in $\mathrm{IIH}^{30,31}$

Enlargement of CSF space or spontaneous CSF-filled outpouchings of the dura (meningoceles) resulting from chronic intracranial hypertension may be the supportive findings in diagnosis of IIH. ${ }^{31}$ These enlargements have been reported in the Meckel's cave, the oculomotor nerve sheath, and the CSF spaces around the abducens nerve..$^{31,32}$

Stenosis of the transverse sinus is another common finding in IIH, which can lead to venous outflow obstruction. Stenosis within dural sinus system has been reported in $30 \%-93 \%$ of IIH patients. ${ }^{33}$ The volume of the entire dural sinus system is also decreased in IIH patients. ${ }^{34}$ Stenosis of transverse and sigmoid sinuses detected by MRV are considered as a reliable neuroimaging marker of IIH with high sensitivity (93\%) and specificity $(93 \%) .{ }^{35}$ Even though a study reported that transverse sinus stenosis still persists after lumbar puncture (LP), ${ }^{36}$ cerebral sinus diameter and dural sinus volumes are significantly increased after normalization of ICP in IIH independent of resolving of transverse sinus stenosis. $^{34,37}$ It is still inconclusive whether venous sinus stenosis is a causative factor or a consequence of intracranial hypertension. Acute CSF volume reduction by CSF diversion or single LP can decrease stenosis of venous sinuses. On the contrary, stenting of transverse sinus stenosis can improve intracranial hypertension. These findings suggest that venous sinus stenosis and intracranial hypertension may have a circular loop relationship. ${ }^{38,39}$

Intraorbital imaging shows enlarged optic nerve sheath, posterior globe flattening, or optic nerve head protrusion. Transorbital ultrasonography is a reliable and noninvasive imaging technique to detect enlargement of the optic nerve sheath diameter (ONSD) with satisfactory sensitivity (90\%) and specificity $(84 \%)$ at a cutoff value of $5.8 \mathrm{~mm}$ in detection of IIH. In another study, ONSD $>5.5 \mathrm{~mm}$ predicted CSF pressure $\geq 20 \mathrm{~cm} \mathrm{H}_{2} \mathrm{O}$ with both sensitivity and specificity of $100 \%{ }^{40}$ Another study showed that ONSD $>5 \mathrm{~mm}$ can detect ICP $>20 \mathrm{~cm} \mathrm{H}_{2} \mathrm{O}$ with sensitivity of $88 \%$ and specificity of $93 \% .{ }^{41}$ Optic disc elevation can also be detected by ultrasound. ${ }^{42} \mathrm{MRI}$ is another reliable imaging modality for the detection of increased ONSD with sensitivity of $72 \%-80 \%$ and specificity of $96 \% .{ }^{43}$ ONSD decreases after LP within 30 minutes, while optic disc protrusion requires longer treatment time for reduction. ${ }^{44-46}$

Flattening of the posterior globe in MRI is highly specific, but not sensitive, in detection of $\mathrm{IIH} .{ }^{43}$ A study reported $100 \%$ specificity of this finding, indicating that it strongly supports the diagnosis of IIH. ${ }^{47}$ It is important to emphasize that even though these findings on imaging provide reliability in differentiating IIH from a normal population without intracranial hypertension, they are not specific for IIH. These signs can also be found in patients with intracranial hypertension from other identifiable causes. ${ }^{48,49}$ For example, empty/partially empty sella sign, flattening of the globes, and dilatation/ tortuosity of the optic nerve sheath were reported in $65 \%$, $42 \%$, and $16 \%$ patients with cerebral venous thrombosis, respectively. ${ }^{48}$

\section{Ophthalmological examination}

Compression of optic nerve and optic nerve ischemia are the two major theories explaining papilledema caused by elevated ICP in IIH. ${ }^{50}$ Papilledema is one of the hallmarks for diagnosis of IIH. Even though, papilledema is commonly symmetric or only mildly asymmetric, significant asymmetry may be found in some patients and can be explained by difference in size of bony optic canals or variation of trabecular meshwork in subarachnoid space surrounding optic discs. ${ }^{51,52}$ Unilateral papilledema is not commonly reported. ${ }^{53,54}$

Fundoscopic examination is very important to evaluate this condition. Frisén's ${ }^{55}$ criteria has been widely accepted for grading severity of papilledema. It is very important to dif- 
ferentiate true papilledema from pseudoedema, which is the physiologic variant, or benign changes of the optic disc. Findings from funduscopic examination showed that the presence of retinal or choroidal folds is a pathognomonic sign of true papilledema. However, this finding was seen only in $23 \%$ of the patients with true papilledema. The combination of four features from funduscopic examination, including the swelling of the peripapillary retinal nerve fiber layer, peripapillary hemorrhages, papilla elevation, and congestion of peripapillary vessels, provides very good validity in differentiating true papilledema from pseudoedema (accuracy 93\%, sensitivity $95 \%$, and specificity $89 \%) .{ }^{56}$

Optical coherence tomography is a noninvasive imaging tool used to evaluate optic nerve status including the severity of papilledema either by measuring fast retinal nerve fiber layer thickness or total retinal thickness. ${ }^{57}$ High-resolution three-dimensional T2-weighted imaging performed at submillimeter slice thickness can effectively detect papilledema. ${ }^{58}$ In diffusion-weighted imaging, hyperintensity of optic nerve head at diagnosis of IIH was found to be correlated with the severity of papilledema. ${ }^{59}$ Macular thickness is significantly reduced in patients with resolved chronic papilledema, which is also correlated with severity of visual field loss. Macular thickness may be an indicator of ganglion cell loss in IIH patients with papilledema. ${ }^{60}$

\section{Idiopathic intracranial hypertension without papilledema}

Idiopathic intracranial hypertension without papilledema (IIHWOP) is the variant of IIH, which was reported in $5.7 \%$ of IIH patients in one study. ${ }^{61}$ IIHWOP is found in $10 \%-14 \%$ of patients with chronic daily headache who fulfilled the criteria for migraine. ${ }^{14,62}$ In patients with migraine, $6.7 \%$ had bilateral transverse sinus stenosis, of which $67.8 \%$ had IIHWOP ${ }^{63}$ In a similar manner, bilateral transverse sinus stenosis was found in $9 \%$ of patients with chronic tension-type headache, and $69.2 \%$ of these patients had IIHWOP ${ }^{64}$ IIHWOP must be considered in patients with chronic daily headache with evidence of sinus stenosis and unresponsiveness to medical management. MRV can detect venous sinus stenosis which is a strong predictor for intracranial hypertension in such patients. LP should be done to confirm the diagnosis..$^{65,66}$

\section{Lumbar puncture}

LP is classically contraindicated in the setting of elevated ICP. However, this procedure is routinely performed in IIH either for diagnostic or for therapeutic purposes. Real-time ONSD reduction and opening of the collapsed transverse sinuses were observed after a bedside LP. ${ }^{45,67}$ Long-standing clinical remission is not uncommon within a single or few sessions of LP. ${ }^{67}$ Amount of removed CSF or a dural hole during single LP may not be the only explanations for longstanding clinical remission. This finding may be explained by the circular loop relationship between CSF and cerebral venous pressure. Removal of CSF by LP is compensated by enlargement of cerebral venous diameters resulting in cerebral venous pressure reduction and enhancing CSF outflow which can promote further venous enlargement. ${ }^{39}$

It is important to note that LP is not a harmless procedure in IIH patients. To date, two cases of tonsillar herniation after LP were reported in IIH patients with preexisting low-lying cerebellar tonsil and worsening metabolic acidosis. ${ }^{6-70}$

\section{Current management}

The primary goal of treatment of $\mathrm{IIH}$ is to prevent visual loss and decrease headache and other symptoms associated with intracranial hypertension. Routine follow-up by neuroophthalmologist or ophthalmologist is very essential for reassessing visual status and degree of papilledema. Weight reduction counseling and medical management are generally sufficient in most patients. Surgery is required only in patients who have severe visual loss, progressive visual loss, or intractable headache despite aggressive medical management. Aggressive weight reduction is necessary in obese patients. Gastric bypass surgery has been demonstrated to improve visual outcomes and reduce ICP in IIH cases with morbid obesity. ${ }^{71,72}$

Although there are many options for the treatment of IIH, the most recent Cochrane review reported that there is insufficient information to generate an evidence-based management for $\mathrm{IIH}^{73}$

\section{Pharmacotherapy}

To date, acetazolamide and topiramate are the only two medications that have been studied in randomized controlled trials for their treatment efficacy in adults with IIH. The efficacy of other medications is only supported by case reports or case series. For example, there was a case series reporting the efficacy of combination of acetazolamide and furosemide in eight children in $1994 .{ }^{74}$ Corticosteroid was reported to be effective in the short-term in patients who presented with severe papilledema and severe visual loss. However, steroid withdrawal and its side effect on weight gain are precipitating factors for worsening IIH in long-term use. A summary of the trials of acetazolamide and topiramate in treatment of IIH in adults are discussed in the following sections. 


\section{Acetazolamide}

Acetazolamide inhibits carbonic anhydrase enzyme in the choroid plexus resulting in decreased CSF production and pressure. It is considered as the first-line medication for IIH. The side effects of acetazolamide generally include paresthesia of extremities, loss of appetite, transient myopia, and metabolic acidosis.

The Neuro-Ophthalmology Research Disease Investigator Consortium (NORDIC) IIH study groups carried out the first multicenter, double-blinded, randomized controlled trial of the efficacy of acetazolamide in 165 patients with IIH and mild visual loss who received low-sodium and weight reduction diet at 6-month period. ${ }^{75}$ The use of acetazolamide with a low-sodium and weight reduction diet moderately improved a visual field defect compared to diet alone. Papilledema and visual-related quality of life were significantly improved in acetazolamide group. Moreover, patients in acetazolamide group also had significant reduction in weight, with an average reduction of $7.5 \mathrm{~kg}$. The effect of acetazolamide on visual function was found more frequently in patients with high-grade papilledema. The dose of acetazolamide used in this trial was maximal at $4 \mathrm{~g} / \mathrm{d}$ (mean: $2.5 \mathrm{~g} / \mathrm{d}$ ). Even though, the finding was statistically significant, the less-than-expected difference of visual field improvement between two groups made the authors caution that "the clinical importance of this improvement remains to be determined."

\section{Topiramate}

Topiramate is an anticonvulsant, which has been previously reported to be effective in the treatment of IIH. ${ }^{76-78}$ There was an open-label, randomized study to compare the efficacy of topiramate (20 patients) and acetazolamide (20 patients). ${ }^{79}$ The doses of topiramate and acetazolamide ranged from $100-150 \mathrm{mg} / \mathrm{d}$ to $1-1.5 \mathrm{~g} / \mathrm{d}$, respectively. This study demonstrated no significant difference in visual field improvement between these two groups at the end of the months 3, 6, and 12. Relief of headache and improvement of papilledema were comparable between two groups. The improvement in headache was seen after 3.75 months in the topiramate group and 3.30 months in the acetazolamide group. This is the first open-label, randomized study on the efficacy of topiramate on the treatment of IIH. However, the number of subjects was small (total: 40 subjects in this study). A larger multicenter, double-blinded, randomized controlled trial would be the next step to confirm the efficacy of topiramate in IIH.

The mechanism of topiramate in IIH treatment is explained by its mild effect on carbonic anhydrase inhibition.
The common side effects of topiramate are distal paresthesia, concentration difficulty, weight loss, and nephrolithiasis. Rare cases of acute angle-closure glaucoma and myopia were reported ${ }^{80-82}$ As topiramate is a prophylactic medication for other forms of headache including migraine, it may be particularly effective in IIH patients without papilledema or in IIH patients with migraine who have intractable headache after resolution of papilledema. ${ }^{83}$

\section{Surgical management}

Generally, surgical intervention is indicated in IIH cases with severe optic neuropathy or medical treatment failure that are vision-threatening. Surgical intervention for IIH includes CSF diversion and optic nerve sheath fenestration (ONSF).

\section{CSF diversion}

CSF diversion by a ventriculoperitoneal shunt (VPS) and lumboperitoneal shunt (LPS) are the most widely used methods to divert CSF from the ventricle or subarachnoid space to peritoneal space. Ventriculoatrial shunt (VAS) is another alternative method to divert CSF from ventricle to right atrium.

LPS has the advantage of avoiding an intracranial approach, thus decreasing the incidence of surgery-related intracranial complications such as intracranial infection and subdural hemorrhage. However, it can cause cerebellar tonsillar descent leading to iatrogenic Chiari malformation. Other complications of CSF diversion are shunt infection, catheter migration, shunt obstruction, and overdrainage. LPS has a higher complication rate than VPS. ${ }^{84}$ Moreover, LPS often requires more revision and greater overall cost than VPS..$^{84-87}$

In terms of clinical outcomes, LPS improved headache in $71 \%-92 \%$ of IIH patients who experienced progressive visual loss or were not responsive to medical treatment. ${ }^{84,88}$ However, recurrent headache was usually found during the follow-up period. ${ }^{85,89}$ Visual acuity was improved by LPS in $42 \%-91 \%$ of patients. ${ }^{84,86}$ Visual field and papilledema were also improved after the procedure. VPS and VAS were less studied than LPS in their role of IIH treatment. These procedures are also effective in improving headache and visual function in patients with IIH. Headache was improved in $60 \%-90 \%$ of the patients after the procedure. ${ }^{84,86}$ VPS and VPA effectively improved visual functions and papilledema. Visual acuity improved in $40 \%-100 \%$, while papilledema resolved in $56 \%-87 \%$ of cases. ${ }^{84,86,89,90}$ Image-guidance is recommended for placement of VPS. ${ }^{11,92}$ 
A recent case series including five patients with IIH refractory to standard periotoneal therapy reported the role of lumbopleural shunt to divert CSF. The complications of this procedure were pleural effusion, hydrothorax, and pneumothorax. The average survival time of the lumbopleural shunt was 48 months (ranged from 2 to 178 months). However, the clinical improvement of IIH was not reported in this study. ${ }^{93}$ Fluoroscopy-guided percutaneous placement of catheter in the perimedullary cistern is reported as an alternative CSF diversion method in two IIH patients with multiple proximal shunt failure. ${ }^{94}$

In conclusion, most of the studies reported similar clinical outcomes (headache, visual function) between LPS and VPS/ VAS. However, LPS has a higher shunt revision rate associated with increased shunt obstruction. Table 2 summarizes the studies on the CSF diversion in IIH treatment.

\section{Optic nerve sheath fenestration}

ONSF is another surgical intervention to reduce papilledemarelated visual loss. This procedure is used primarily to reduce CSF pressure on retrolaminar part of the optic nerve. However, it may not decrease ICP. Thus, this method is preferred in IIH patients who mainly experience visual symptoms. The majority of studies also emphasized the visual outcomes (visual acuity, visual flied, and papilledema) more than outcome on headache reduction.

In terms of efficacy, ONSF demonstrates very satisfactory outcomes. Improvement or stabilization of visual acuity and visual field are reported in a very wide range, from $60 \%$ to $100 \%$, of cases depending on the criteria of each study. Papilledema was improved in $71 \%-100 \%$ of patients after the procedure. Even though ONSF locally decrease CSF pressure surrounding an optic nerve with very minimal effect on the overall ICP, improvement of headache was reported after this procedure in $13 \%-90 \%$ of cases. Table 3 summarizes the outcomes of ONSF in IIH.

In the past, there was a suggestion that, in case of bilateral visual loss or papilledema, CSF diversion can decrease the need for bilateral ONSF. However, some studies also reported the improvement of bilateral papilledema and visual function after unilateral ONSF. ${ }^{95-98}$ In comparison to CSF diversion, ONSF is less invasive and does not require leaving any foreign body in the central nervous system. The rate of infection is minimal. The majority of complications are often minimal and transient, which include diplopia, anisocoria, and corneal drusen. Major complications were rarely reported, including central retinal artery occlusion, acute angle-closure glaucoma, iatrogenic traumatic optic neuropathy, and infectious optic neuropathy ${ }^{99-102}$ In the early postoperative period, fluid collection adjacent to the dural window site occurs in majority of the patients, but this disappears in the late period. ${ }^{96,103}$ Protracted postsurgical blindness can occur after ONSF, and patients subsequently recover in some cases. ${ }^{104}$

\section{Endovascular venous stenting}

Venous stenosis is detected in a significant number of $\mathrm{IIH}$ patients. It is still unclear whether venous stenosis directly causes intracranial hypertension due to impaired cerebral venous return or is the consequence of vascular compression from long-standing intracranial hypertension. Previous studies demonstrated that fixing the stenosis by endovascular stenting decreased venous pressure gradient and ICP in subgroup of IIH patients who have a venous pressure gradient across the stenosis. ${ }^{105-108}$ Even in bilateral stenosis, unilateral stent is sufficient to decrease the venous pressure gradient. ${ }^{105}$ In terms of cost, there is no cost difference between the initial insertion of stent or CSF shunting. However, considering the high revision rate of CSF shunting, venous stenting costs significantly less than CSF shunting. ${ }^{109}$

From the pooling analysis of nine retrospective studies (total 174 cases), this procedure provided satisfactory outcomes during the mean follow-up period of 23 months. ${ }^{105-108,111-114}$ Among 129 patients who had headache, 99 patients (77\%) had improvement or resolution of headache after the stent insertion. Of 54 patients documented to have visual problem, visual acuity was improved or stabilized in 48 patients (89\%) and papilledema was resolved or improved in 109 from 117 patients (93\%). Of the 51 patients who presented with pulsatile tinnitus, it was resolved in 48 patients (94\%) after stent placement. Table 4 summarizes the outcomes of endovascular venous stenting in IIH.

The common complications of venous sinus stenting are ipsilateral headache in $20 \%-100 \%$ of cases; this resolves within few days after the procedure. Intracranial hemorrhage is a serious complication that is rarely seen after the procedure $(4 \%-6 \%)$. Proximal stent stenosis was found in some studies with unclear etiology. ${ }^{105,110}$ In contrast to an arterial stenting, in-stent stenosis is very rare in venous sinus stenting. Aspirin and clopidogrel are generally required for 3-4 days prior to the procedure and are continued for 3-6 months after the placement before clopidogrel is discontinued. ${ }^{105,110}$

Various cutoff points for mean pressure gradients have been postulated in different studies ranged from 4 to $10 \mathrm{mmHg}$ prior to the procedure. Some studies did not consider this pressure gradient. ${ }^{105,106,108,110,112}$ Further research is needed to identify the 


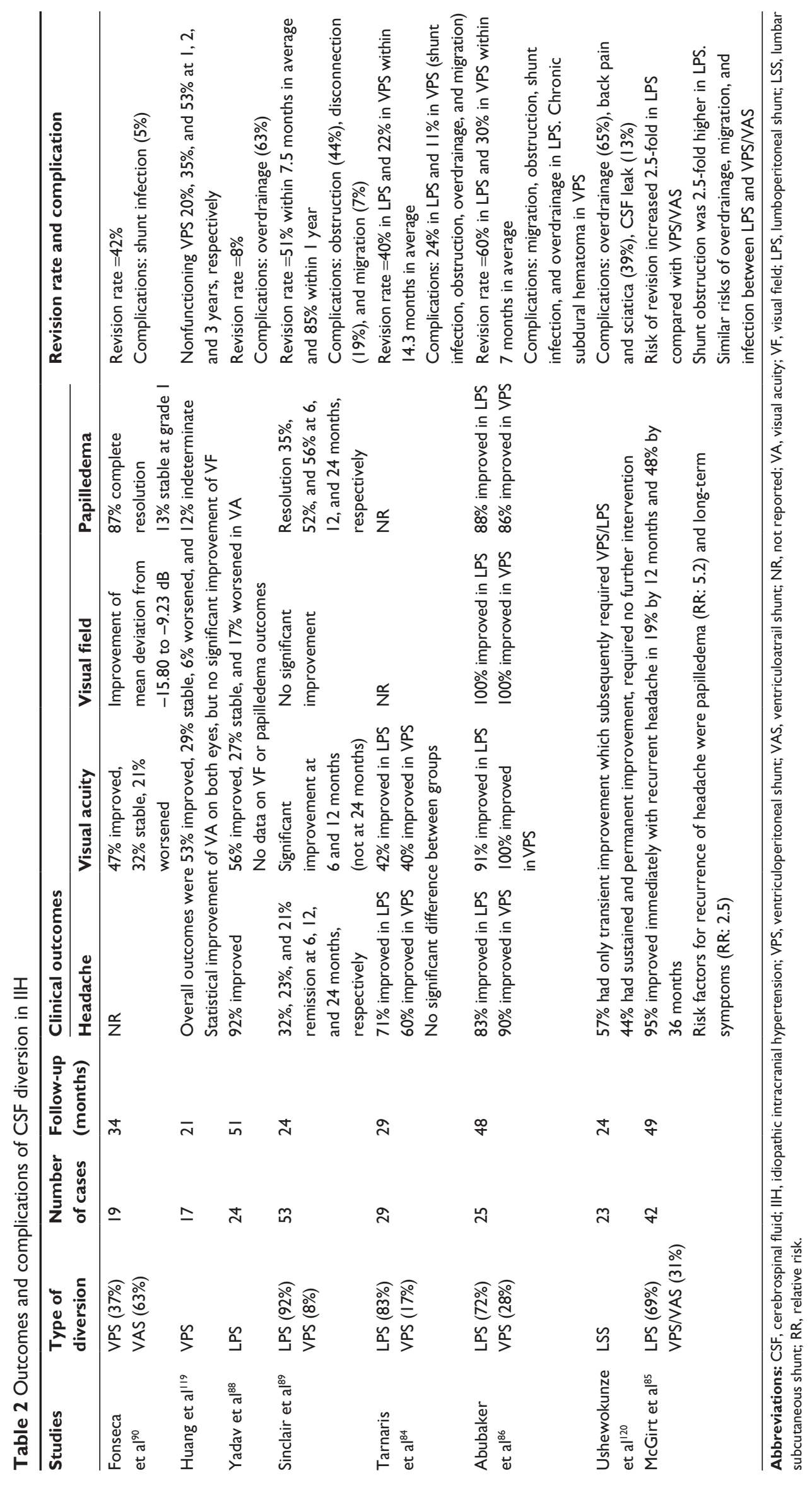



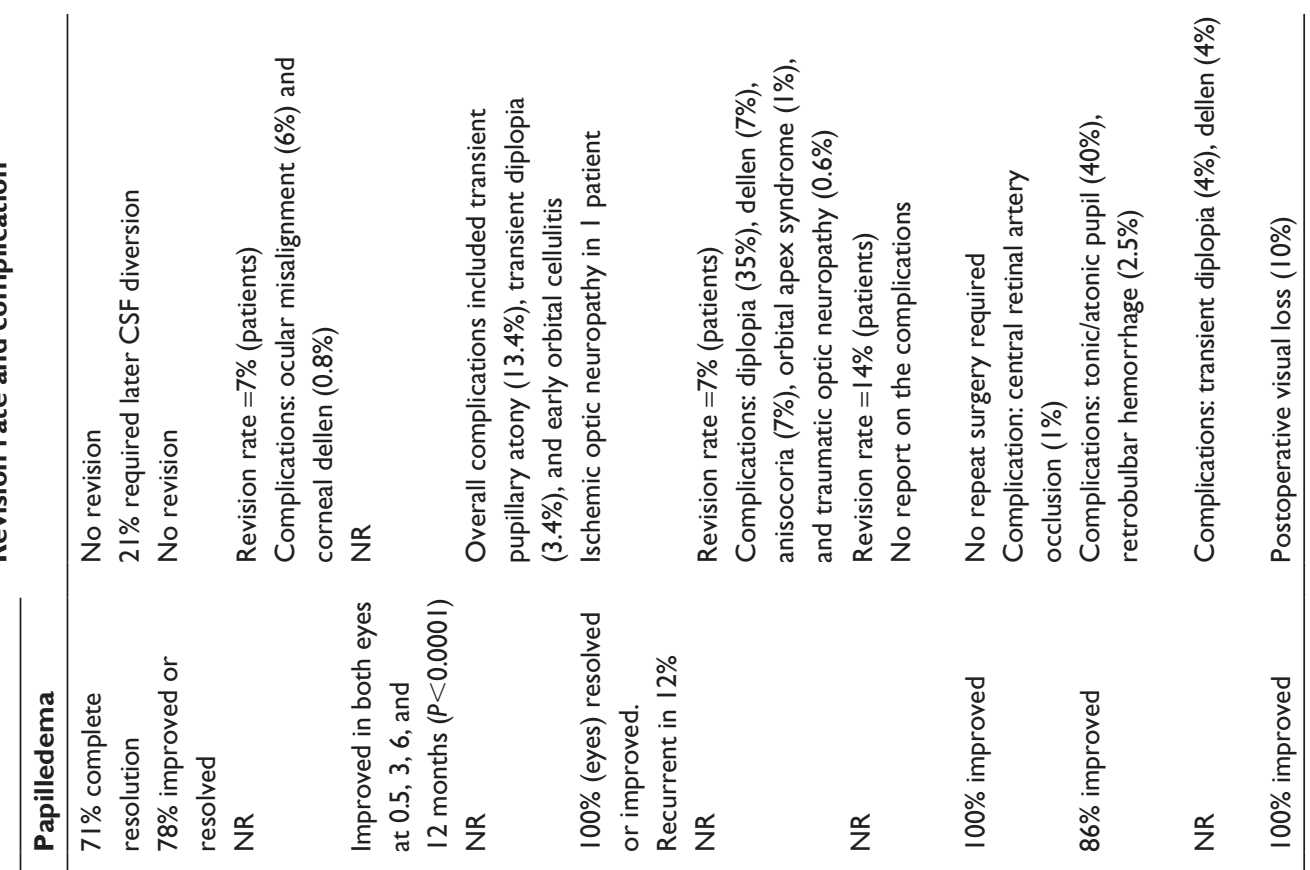

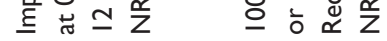

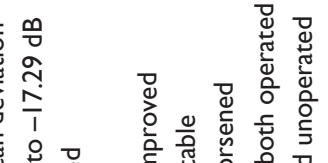

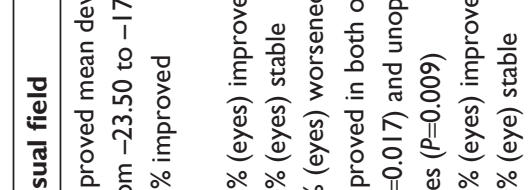

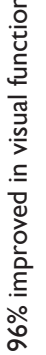

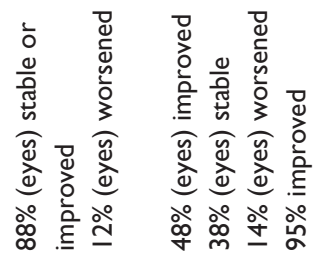

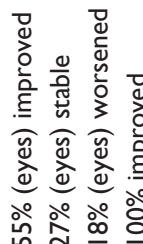

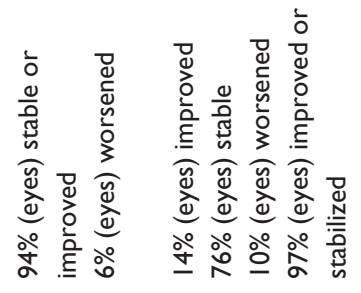

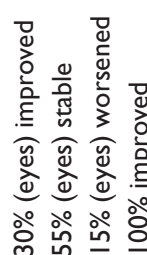

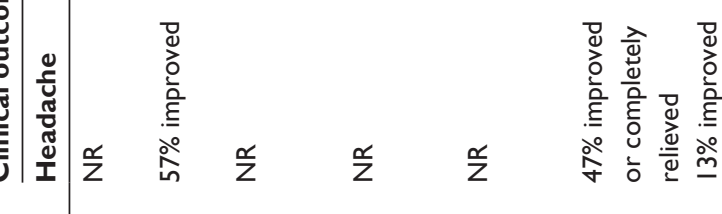




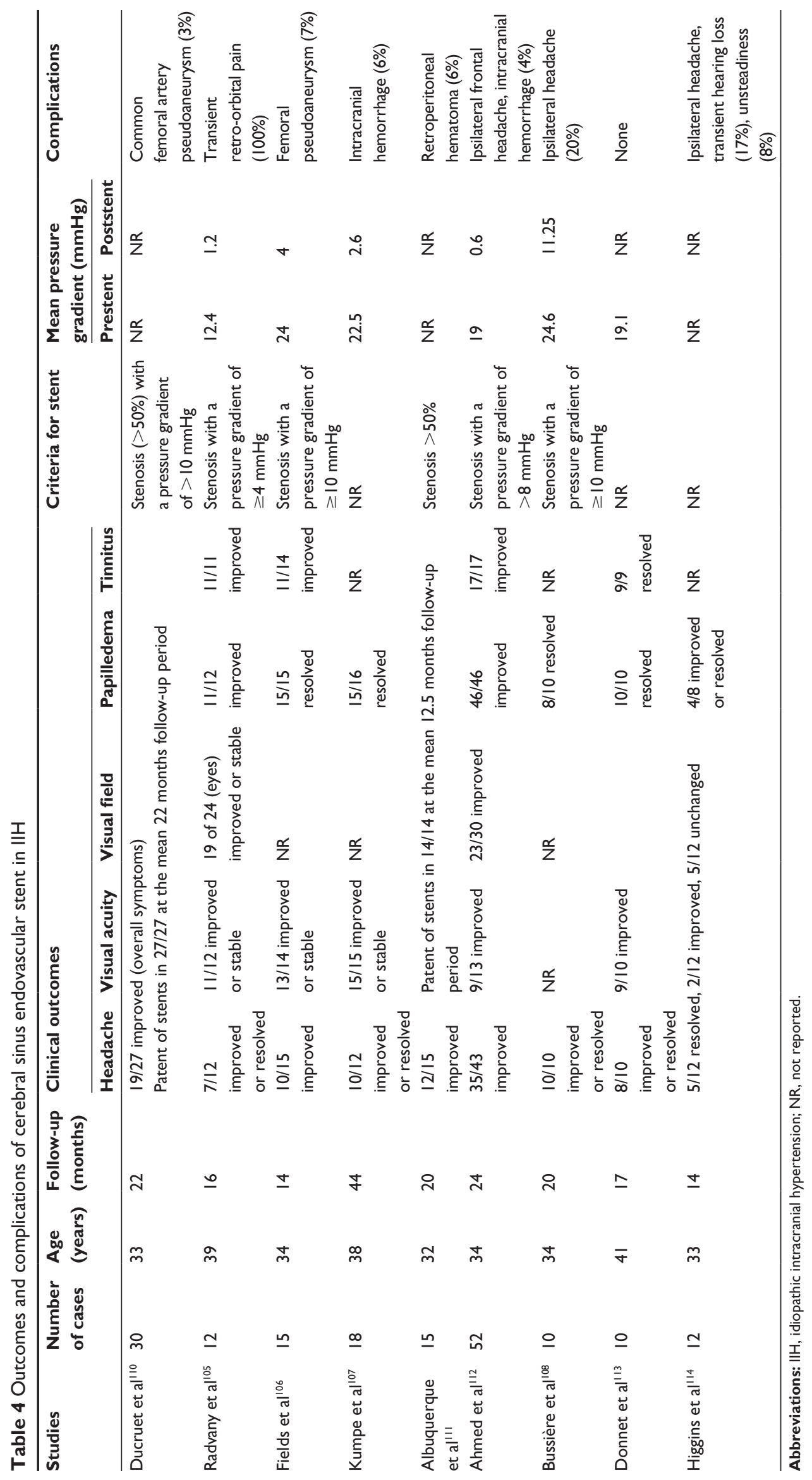


Table 5 Long-term outcomes of the intervention to visual function and headache when follow-up $>$ I year

\begin{tabular}{|c|c|c|c|c|c|c|c|c|}
\hline \multirow[t]{2}{*}{ Procedures } & \multirow{2}{*}{$\begin{array}{l}\text { Number } \\
\text { of studies }\end{array}$} & \multirow{2}{*}{$\begin{array}{l}\text { Number } \\
\text { of cases }\end{array}$} & \multirow{2}{*}{$\begin{array}{l}\text { Follow-up } \\
\text { (months) }\end{array}$} & \multicolumn{5}{|c|}{ Clinical outcomes } \\
\hline & & & & $\begin{array}{l}\text { Headache } \\
\text { improvement } \\
\text { (range) }\end{array}$ & $\begin{array}{l}\text { Visual acuity } \\
\text { improvement } \\
\text { (range) }\end{array}$ & $\begin{array}{l}\text { Visual field } \\
\text { improvement } \\
\text { (range) }\end{array}$ & $\begin{array}{l}\text { Papilledema } \\
\text { improvement } \\
\text { (range) }\end{array}$ & $\begin{array}{l}\text { Revision rate } \\
\text { of procedure } \\
\text { (range) }\end{array}$ \\
\hline $\begin{array}{l}\text { Optic nerve sheath } \\
\text { fenestration }\end{array}$ & 8 & 432 & 20 & $26 \%(13 \%-90 \%)$ & $42 \%(17 \%-100 \%)$ & $72 \%(48 \%-100 \%)$ & $92 \%(79 \%-100 \%)$ & $6.5 \%(5 \%-21 \%)$ \\
\hline CSF diversion & 7 & 209 & 39 & $55 \%(21 \%-92 \%)$ & $56 \%(40 \%-93 \%)$ & $77 \%(64 \%-100 \%)$ & $70 \%(56 \%-87 \%)$ & $44 \%(8 \%-85 \%)$ \\
\hline Cerebral sinus & 9 & 174 & 23 & $77 \%(58 \%-100 \%)$ & $89 \%$ (69\%-100\%) & $79 \%(77 \%-79 \%)$ & $93 \%$ (50\%-100\%) & NA \\
\hline
\end{tabular}

endovascular stent

Abbreviations: CSF, cerebrospinal fluid; NA, not applicable.

optimum gradient and severity of venous stenosis amenable for the selection of patients for endovascular stenting.

In IIH patients with focal venous sinus stenosis, emphasis on the management of sinus stenosis by stenting is a new emerging treatment option providing very satisfactory clinical outcomes and low rate of complications or revision.

\section{Future prospects}

\section{Biomarkers or diagnostic development}

The pathogenesis of IIH remains unknown. Some studies demonstrated the presence of oligoclonal bands in IIH patients that is associated with vision loss. ${ }^{115}$ Patients with IIH had significantly higher serum levels of TNF- $\alpha$, IFN- $\gamma$, IL-4, IL-10, IL-12, and IL-17 in comparison to multiple sclerosis patients and normal controls. IL-2, IL-4, IL-10, IL-17, and IFN- $\gamma$ levels in CSF were higher in IIH patients compared to patients with multiple sclerosis or nonorganic/noninflammatory neurologic conditions. ${ }^{116}$ These findings may support the immunologic role in pathogenesis of IIH. ${ }^{115-117}$

There is a study aimed at identifying the CSF proteome in IIH patients as the new biomarkers. Six proteins were upregulated in IIH, namely, sterol regulatory elementbinding protein 1 , zinc- $\alpha$-2-glycoprotein, immunoglobulin heavy constant $\alpha-1, \alpha-1$-antitrypsin, serotransferrin, and haptoglobin. Four proteins were downregulated in IIH, including hemopexin, angiotensinogen, vitamin-D-binding protein, and transthyretin. Angiotensinogen was the first protein validated in the study, and it was found that downregulation of angiotensinogen may contribute to the increased CSF production, which subsequently causes IIH. The study of other proteins may provide more knowledge on the new biomarkers for diagnosis of IIH. Moreover, these proteins may be the target for therapeutic intervention. ${ }^{118}$

\section{Conclusion}

$\mathrm{IIH}$ is an uncommon disorder characterized by symptoms and signs of intracranial hypertension without radiologic or laboratory evidence of intracranial pathology. This condition typically affects young-to-middle-aged females with obesity. Visual impairment and severe headache are the major concerns in this condition; thus, the primary treatment purpose is to prevent visual dysfunction and reduce headache severity. Counseling about weight reduction is the initial treatment approach in all obese patients. LP is a diagnostic tool for evaluation of elevated ICP. Medical management is generally the first line of treatment and is adequate in the majority of patients. Acetazolamide and topiramate are the only two medications that have been studied in randomized controlled trials and showed significant improvement of headache and visual outcomes. Acetazolamide is the first-line medication in most patients. In patients with severe optic neuropathy or those who fail medical therapy, surgical management, either CSF diversion or ONSF, and endovascular venous stenting of transverse sinus stenosis are the next available options which have demonstrated satisfactory outcomes on visual function and headache. Table 5 summarizes the long-term outcome of visual function and headache of each intervention in the treatment of refractory IIH. There are many challenges that need to be explored in future research on the diagnosis and treatment of IIH. Many biomarkers have been demonstrated to relate to IIH pathogenesis and may be the targets in the future research. In addition, more prospective, randomized controlled trials are needed to establish a treatment guideline for IIH.

\section{Disclosure}

The authors report no conflicts of interest in this work.

\section{References}

1. Radhakrishnan K, Thacker AK, Bohlaga NH, Maloo JC, Gerryo SE. Epidemiology of idiopathic intracranial hypertension: a prospective and case-control study. J Neurol Sci. 1993;116(1):18-28.

2. Yabe I, Moriwaka F, Notoya A, Ohtaki M, Tashiro K. Incidence of idiopathic intracranial hypertension in Hokkaido, the northernmost island of Japan. J Neurol. 2000;247(6):474-475.

3. Kesler A, Gadoth N. Epidemiology of idiopathic intracranial hypertension in Israel. J Neuroophthalmol. 2001;21(1):12-14. 
4. Raoof N, Sharrack B, Pepper IM, Hickman SJ. The incidence and prevalence of idiopathic intracranial hypertension in Sheffield, UK. Eur J Neurol. 2011;18(10):1266-1268.

5. Carta A, Bertuzzi F, Cologno D, Giorgi C, Montanari E, Tedesco S. Idiopathic intracranial hypertension (pseudotumor cerebri): descriptive epidemiology, clinical features, and visual outcome in Parma, Italy, 1990 to 1999. Eur J Ophthalmol. 2004;14(1):48-54.

6. Craig JJ, Mulholland DA, Gibson JM. Idiopathic intracranial hypertension; incidence, presenting features and outcome in Northern Ireland (1991-1995). Ulster Med J. 2001;70(1):31-35.

7. Radhakrishnan K, Sridharan R, Ashok PP, Mousa ME. Pseudotumour cerebri: incidence and pattern in North-Eastern Libya. Eur Neurol. 1986;25(2):117-124.

8. McCluskey G, Mulholland DA, McCarron P, McCarron MO. Idiopathic intracranial hypertension in the Northwest of Northern Ireland: epidemiology and clinical management. Neuroepidemiology. 2015;45(1): 34-39.

9. Durcan FJ, Corbett JJ, Wall M. The incidence of pseudotumor cerebri. Population studies in Iowa and Louisiana. Arch Neurol. 1988;45(8): 875-877.

10. Digre KB, Bruce BB, McDermott MP, Galetta KM, Balcer LJ, Wall M. Quality of life in idiopathic intracranial hypertension at diagnosis: IIH Treatment Trial results. Neurology. 2015;84(24) 2449-2456.

11. Wall M. The headache profile of idiopathic intracranial hypertension. Cephalalgia. 1990;10(6):331-335.

12. Wall M, Kupersmith MJ, Kieburtz KD, et al. The idiopathic intracranial hypertension treatment trial: clinical profile at baseline. JAMA Neurol. 2014;71(6):693-701.

13. Johnston I, Paterson A. Benign intracranial hypertension. II. CSF pressure and circulation. Brain. 1974;97(2):301-312.

14. Mathew NT, Ravishankar K, Sanin LC. Coexistence of migraine and idiopathic intracranial hypertension without papilledema. Neurology 1996;46(5):1226-1230.

15. Headache Classification Committee of the International Headache Society (IHS). The International Classification of Headache Disorders, 3rd edition (beta version). Cephalalgia. 2013;33(9):629-808.

16. Jindal M, Hiam L, Raman A, Rejali D. Idiopathic intracranial hypertension in otolaryngology. Eur Arch Otorhinolaryngol. 2009;266(6): 803-806.

17. Sismanis A, Callari RH, Slomka WS, Butts FM. Auditory-evoked responses in benign intracranial hypertension syndrome. Laryngoscope. 1990;100(11):1152-1155.

18. Zur D, Naftaliev E, Kesler A. Evidence of multidomain mild cognitive impairment in idiopathic intracranial hypertension. J Neuroophthalmol. 2015;35(1):26-30

19. Yri HM, Fagerlund B, Forchhammer HB, Jensen RH. Cognitive function in idiopathic intracranial hypertension: a prospective case-control study. BMJ Open. 2014;4(4):e004376.

20. Kharkar S, Hernandez R, Batra S, et al. Cognitive impairment in patients with pseudotumor cerebri syndrome. Behav Neurol. 2011;24(2): 143-148.

21. Bershad EM, Urfy MZ, Calvillo E, et al. Marked olfactory impairment in idiopathic intracranial hypertension. J Neurol Neurosurg Psychiatry. 2014;85(9):959-964.

22. Kunte H, Schmidt F, Kronenberg G, et al. Olfactory dysfunction in patients with idiopathic intracranial hypertension. Neurology. 2013;81(4):379-382.

23. Kapoor KG. Do patients with idiopathic intracranial hypertension suffer from hyposmia? Med Hypotheses. 2008;71(5):816-817.

24. Khoo KF, Kunte H. Olfactory dysfunction in patients with idiopathic intracranial hypertension. Neurology. 2014;82(2):189.

25. Schmidt C, Wiener E, Hoffmann J, et al. Structural olfactory nerve changes in patients suffering from idiopathic intracranial hypertension. PLoS One. 2012;7(4):e35221.

26. Kyung SE, Botelho JV, Horton JC. Enlargement of the sella turcica in pseudotumor cerebri. J Neurosurg. 2014;120(2):538-542.
27. Ranganathan S, Lee SH, Checkver A, et al. Magnetic resonance imaging finding of empty sella in obesity related idiopathic intracranial hypertension is associated with enlarged sella turcica. Neuroradiology. 2013;55(8):955-961.

28. Degnan AJ, Levy LM. Narrowing of Meckel's cave and cavernous sinus and enlargement of the optic nerve sheath in pseudotumor cerebri. J Comput Assist Tomogr. 2011;35(2):308-312.

29. Butros SR, Goncalves LF, Thompson D, Agarwal A, Lee HK. Imaging features of idiopathic intracranial hypertension, including a new finding: widening of the foramen ovale. Acta Radiol. 2012;53(6):682-688.

30. Saindane AM, Bruce BB. Reply to "Enlarged CSF spaces in pseudotumor cerebri”. AJR Am J Roentgenol. 2014;203(4):W459.

31. Bialer OY, Rueda MP, Bruce BB, Newman NJ, Biousse V, Saindane AM. Meningoceles in idiopathic intracranial hypertension. AJR Am J Roentgenol. 2014;202(3):608-613.

32. San Millán D, Kohler R. Enlarged CSF spaces in pseudotumor cerebri. AJR Am J Roentgenol. 2014;203(4):W457-W458.

33. Puffer RC, Mustafa W, Lanzino G. Venous sinus stenting for idiopathic intracranial hypertension: a review of the literature. J Neurointerv Surg. 2013;5(5):483-486.

34. Rohr A, Bindeballe J, Riedel C, et al. The entire dural sinus tree is compressed in patients with idiopathic intracranial hypertension: a longitudinal, volumetric magnetic resonance imaging study. Neuroradiology. 2012;54(1):25-33.

35. Farb RI, Vanek I, Scott JN, et al. Idiopathic intracranial hypertension: the prevalence and morphology of sinovenous stenosis. Neurology. 2003;60(9):1418-1424.

36. Bono F, Giliberto C, Mastrandrea C, et al. Transverse sinus stenoses persist after normalization of the CSF pressure in IIH. Neurology. 2005;65(7):1090-1093.

37. Horev A, Hallevy H, Plakht Y, Shorer Z, Wirguin I, Shelef I. Changes in cerebral venous sinuses diameter after lumbar puncture in idiopathic intracranial hypertension: a prospective MRI study. J Neuroimaging. 2013;23(3):375-378.

38. De Simone R, Ranieri A, Montella S, Bilo L, Cautiero F. The role of dural sinus stenosis in idiopathic intracranial hypertension pathogenesis: the self-limiting venous collapse feedback-loop model. Panminerva Med. 2014;56(3):201-209.

39. De Simone R, Ranieri A, Bonavita V. Advancement in idiopathic intracranial hypertension pathogenesis: focus on sinus venous stenosis. Neurol Sci. 2010;31(Suppl 1):S33-S39.

40. Amini A, Kariman H, Arhami Dolatabadi A, et al. Use of the sonographic diameter of optic nerve sheath to estimate intracranial pressure. Am J Emerg Med. 2013;31(1):236-239.

41. Kimberly HH, Shah S, Marill K, Noble V. Correlation of optic nerve sheath diameter with direct measurement of intracranial pressure. Acad Emerg Med. 2008;15(2):201-204.

42. Lochner P, Nardone R, Tezzon F, Coppo L, Brigo F. Optic nerve sonography to monitor treatment efficacy in idiopathic intracranial hypertension: a case report. J Neuroimaging. 2013;23(4):533-534.

43. Hoffmann J, Huppertz H-J, Schmidt C, et al. Morphometric and volumetric MRI changes in idiopathic intracranial hypertension. Cephalalgia. 2013;33(13):1075-1084.

44. Bäuerle J, Nedelmann M. Sonographic assessment of the optic nerve sheath in idiopathic intracranial hypertension. J Neurol. 2011;258(11): 2014-2019.

45. Singleton J, Dagan A, Edlow JA, Hoffmann B. Real-time optic nerve sheath diameter reduction measured with bedside ultrasound after therapeutic lumbar puncture in a patient with idiopathic intracranial hypertension. Am J Emerg Med. 2014;33(6):860. e5-e7.

46. Hassen GW, Nazeer O, Manizate F, Patel N, Kalantari H. The role of bedside ultrasound in pretherapeutic and posttherapeutic lumbar puncture in patient with idiopathic intracranial hypertension. Am J Emerg Med. 2014;32(10):1298. e3-e4.

47. Agid R, Farb RI, Willinsky RA, Mikulis DJ, Tomlinson G. Idiopathic intracranial hypertension: the validity of cross-sectional neuroimaging signs. Neuroradiology. 2006;48(8):521-527. 
48. Ridha MA, Saindane AM, Bruce BB, et al. MRI findings of elevated intracranial pressure in cerebral venous thrombosis versus idiopathic intracranial hypertension with transverse sinus stenosis. Neuroophthalmology. 2013;37(1):1-6.

49. Hingwala DR, Kesavadas C, Thomas B, Kapilamoorthy TR, Sarma PS. Imaging signs in idiopathic intracranial hypertension: are these signs seen in secondary intracranial hypertension too? Ann Indian Acad Neurol. 2013;16(2):229-233.

50. Passi N, Degnan AJ, Levy LM. MR imaging of papilledema and visual pathways: effects of increased intracranial pressure and pathophysiologic mechanisms. AJNR Am J Neuroradiol. 2013;34(5):919-924.

51. Bidot S, Bruce BB, Saindane AM, Newman NJ, Biousse V. Asymmetric papilledema in idiopathic intracranial hypertension. J Neuroophthalmol. 2015;35(1):31-36.

52. Maxner CE, Freedman MI, Corbett JJ. Asymmetric papilledema and visual loss in pseudotumour cerebri. Can J Neurol Sci. 1987;14(4): 593-596.

53. Brosh K, Strassman I. Unilateral papilledema in pseudotumor cerebri. Semin Ophthalmol. 2013;28(4):242-243.

54. Wattamwar PR, Baheti NN, Radhakrishnan A. Idiopathic intracranial hypertension presenting as unilateral papilledema. Neurol India. 2010; 58(5):818-819.

55. Frisén L. Swelling of the optic nerve head: a staging scheme. J Neurol Neurosurg Psychiatry. 1982;45(1):13-18.

56. Carta A, Favilla S, Prato M, Bianchi-Marzoli S, Sadun AA, Mora P. Accuracy of funduscopy to identify true edema versus pseudoedema of the optic disc. Invest Ophthalmol Vis Sci. 2012;53(1):1-6.

57. Scott CJ, Kardon RH, Lee AG, Frisén L, Wall M. Diagnosis and grading of papilledema in patients with raised intracranial pressure using optical coherence tomography vs clinical expert assessment using a clinical staging scale. Arch Ophthalmol. 2010;128(6):705-711.

58. Sotoudeh H, Bowerson M, Parsons M, et al. Effect of spatial resolution of T2-weighted imaging on diagnostic efficacy of MRI in detection of papilledema. AJR Am J Roentgenol. 2015;204(3):602-607.

59. Salvay DM, Padhye LV, Huecker JB, et al. Correlation between papilledema grade and diffusion-weighted magnetic resonance imaging in idiopathic intracranial hypertension. J Neuroophthalmol. 2014;34(4):331-335.

60. Monteiro MLR, Afonso CL. Macular thickness measurements with frequency domain-OCT for quantification of axonal loss in chronic papilledema from pseudotumor cerebri syndrome. Eye (Lond). 2014; 28(4):390-398.

61. Digre KB, Nakamoto BK, Warner JEA, Langeberg WJ, Baggaley SK, Katz BJ. A comparison of idiopathic intracranial hypertension with and without papilledema. Headache. 2009;49(2):185-193.

62. Vieira DS, Masruha MR, Gonçalves AL, et al. Idiopathic intracranial hypertension with and without papilloedema in a consecutive series of patients with chronic migraine. Cephalalgia. 2008;28(6):609-613.

63. Bono F, Messina D, Giliberto C, et al. Bilateral transverse sinus stenosis predicts IIH without papilledema in patients with migraine. Neurology. 2006;67(3):419-423.

64. Bono F, Messina D, Giliberto C, et al. Bilateral transverse sinus stenosis and idiopathic intracranial hypertension without papilledema in chronic tension-type headache. J Neurol. 2008;255(6):807-812.

65. De Simone R, Ranieri A. The role of intracranial hypertension in the chronification of migraine. Neurol Sci. 2015;36(Suppl 1):23-28.

66. De Simone R, Ranieri A, Montella S, Erro R, Fiorillo C, Bonavita V. Sinus venous stenosis-associated IIHWOP is a powerful risk factor for progression and refractoriness of pain in primary headache patients: a review of supporting evidences. Neurol Sci. 2011;32(Suppl 1): S169-S171.

67. De Simone R, Marano E, Fiorillo C, et al. Sudden re-opening of collapsed transverse sinuses and longstanding clinical remission after a single lumbar puncture in a case of idiopathic intracranial hypertension. Pathogenetic implications. Neurol Sci. 2005;25(6):342-344.

68. Hoffman KR, Chan SW, Hughes AR, Halcrow SJ. Management of cerebellar tonsillar herniation following lumbar puncture in idiopathic intracranial hypertension. Case Reports Crit Care. 2015;2015:895035.
69. Borire AA, Hughes AR, Lueck CJ. Tonsillar herniation after lumbar puncture in idiopathic intracranial hypertension. J Neuroophthalmol. 2015;35(3):293-295.

70. Sullivan HC. Fatal tonsillar herniation in pseudotumor cerebri. Neurology. 1991;41(7):1142-1144.

71. Fridley J, Foroozan R, Sherman V, Brandt ML, Yoshor D. Bariatric surgery for the treatment of idiopathic intracranial hypertension. J Neurosurg. 2011;114(1):34-39.

72. Levin AA, Hess D, Hohler AD. Treatment of idiopathic intracranial hypertension with gastric bypass surgery. Int J Neurosci. 2015;125(1): 78-80.

73. Lueck C, McIlwaine G. Interventions for idiopathic intracranial hypertension. Cochrane Database Syst Rev. 2005;(3):CD003434.

74. Schoeman JF. Childhood pseudotumor cerebri: clinical and intracranial pressure response to acetazolamide and furosemide treatment in a case series. J Child Neurol. 1994;9(2):130-134.

75. Wall M, McDermott MP, Kieburtz KD, et al. Effect of acetazolamide on visual function in patients with idiopathic intracranial hypertension and mild visual loss: the idiopathic intracranial hypertension treatment trial. JAMA. 2014;311(16):1641-1651.

76. Pagan FL, Restrepo L, Balish M, Patwa HS, Houff S. A new drug for an old condition? Headache. 2002;42(7):695-696.

77. Finsterer J, Földy D, Fertl E. Topiramate resolves headache from pseudotumor cerebri. J Pain Symptom Manage. 2006;32(5):401-402.

78. Palacio E, Rodero L, Pascual J. Topiramate-responsive headache due to idiopathic intracranial hypertension in Behçet syndrome. Headache. 2004;44(5):436-437.

79. Celebisoy N, Gökçay F, Sirin H, Akyürekli O. Treatment of idiopathic intracranial hypertension: topiramate vs acetazolamide, an open-label study. Acta Neurol Scand. 2007;116(5):322-327.

80. Levy J, Yagev R, Petrova A, Lifshitz T. Topiramate-induced bilateral angle-closure glaucoma. Can J Ophthalmol. 2006;41(2):221-225.

81. Giuliari GP, Banda RM, Vann VR, Gonzalez VH, McMillin RB. Closed-angle glaucoma after topiramate therapy for migraine in a patient with undiagnosed pseudotumor cerebri. Can J Ophthalmol. 2008;43(3):371.

82. Alore PL, Jay WM, Macken MP. Topiramate, pseudotumor cerebri, weight-loss and glaucoma: an ophthalmologic perspective. Semin Ophthalmol. 2006;21(1):15-17.

83. Mallery RM, Friedman DI, Liu GT. Headache and the pseudotumor cerebri syndrome. Curr Pain Headache Rep. 2014;18(9):446.

84. Tarnaris A, Toma AK, Watkins LD, Kitchen ND. Is there a difference in outcomes of patients with idiopathic intracranial hypertension with the choice of cerebrospinal fluid diversion site: a single centre experience. Clin Neurol Neurosurg. 2011;113(6):477-479.

85. McGirt MJ, Woodworth G, Thomas G, Miller N, Williams M, Rigamonti D. Cerebrospinal fluid shunt placement for pseudotumor cerebri-associated intractable headache: predictors of treatment response and an analysis of long-term outcomes. J Neurosurg. 2004;101(4):627-632.

86. Abubaker K, Ali Z, Raza K, Bolger C, Rawluk D, O’Brien D. Idiopathic intracranial hypertension: lumboperitoneal shunts versus ventriculoperitoneal shunts - case series and literature review. Br J Neurosurg. 2011;25(1):94-99.

87. Menger RP, Connor DE, Thakur JD, et al. A comparison of lumboperitoneal and ventriculoperitoneal shunting for idiopathic intracranial hypertension: an analysis of economic impact and complications using the Nationwide Inpatient Sample. Neurosurg Focus. 2014;37(5):E4.

88. Yadav YR, Parihar V, Agarwal M, Bhatele PR, Saxena N. Lumbar peritoneal shunt in idiopathic intracranial hypertension. Turk Neurosurg. 2012;22(1):21-26.

89. Sinclair AJ, Kuruvath S, Sen D, Nightingale PG, Burdon MA, Flint G. Is cerebrospinal fluid shunting in idiopathic intracranial hypertension worthwhile? A 10-year review. Cephalalgia. 2011;31(16): 1627-1633.

90. Fonseca PL, Rigamonti D, Miller NR, Subramanian PS. Visual outcomes of surgical intervention for pseudotumour cerebri: optic nerve sheath fenestration versus cerebrospinal fluid diversion. $\mathrm{Br} J$ Ophthalmol. 2014;98(10):1360-1363. 
91. Woodworth GF, McGirt MJ, Elfert P, Sciubba DM, Rigamonti D. Frameless stereotactic ventricular shunt placement for idiopathic intracranial hypertension. Stereotact Funct Neurosurg. 2005;83(1):12-16.

92. Kandasamy J, Hayhurst C, Clark S, et al. Electromagnetic stereotactic ventriculoperitoneal CSF shunting for idiopathic intracranial hypertension: a successful step forward? World Neurosurg. 2011;75(1): 155-160; discussion 32-33.

93. Elder BD, Sankey EW, Goodwin CR, Jusué-Torres I, Khattab MH, Rigamonti D. Outcomes and experience with lumbopleural shunts in the management of idiopathic intracranial hypertension. World Neurosurg. 2015;84(2):314-319.

94. Johnson JN, Elhammady MS, Theodotou CB,Ashour R, Aziz-Sultan MA. Cervical puncture and perimedullary cistern shunt placement for idiopathic intracranial hypertension: an alternative to lumbar cistern or cerebral ventricular catheter placement a report of two cases. Asian J Neurosurg. 2014;9(3):153-157.

95. Alsuhaibani AH, Carter KD, Nerad JA, Lee AG. Effect of optic nerve sheath fenestration on papilledema of the operated and the contralateral nonoperated eyes in idiopathic intracranial hypertension Ophthalmology. 2011;118(2):412-414.

96. Yazici Z, Yazici B, Tuncel E. Findings of magnetic resonance imaging after optic nerve sheath decompression in patients with idiopathic intracranial hypertension. Am J Ophthalmol. 2007;144(3):429-435.

97. Kelman SE, Heaps R, Wolf A, Elman MJ. Optic nerve decompression surgery improves visual function in patients with pseudotumor cerebri. Neurosurgery. 1992;30(3):391-395.

98. Corbett JJ, Nerad JA, Tse DT, Anderson RL. Results of optic nerve sheath fenestration for pseudotumor cerebri. The lateral orbitotomy approach. Arch Ophthalmol. 1988;106(10):1391-1397.

99. Moreau A, Lao KC, Farris BK. Optic nerve sheath decompression: a surgical technique with minimal operative complications. J Neuroophthalmol. 2014;34(1):34-38.

100. Naqvi SM, Thiagarajah C, Golnik K, Lee A, Kersten R, Nerad J. Optic nerve cyst-like formation presenting as a delayed complication of optic nerve sheath fenestration. Ophthal Plast Reconstr Surg. 2014;30(3): e53-e54.

101. Banta JT, Farris BK. Pseudotumor cerebri and optic nerve sheath decompression. Ophthalmology. 2000;107(10):1907-1912.

102. Mauriello JA, Shaderowfsky P, Gizzi M, Frohman L. Management of visual loss after optic nerve sheath decompression in patients with pseudotumor cerebri. Ophthalmology. 1995;102(3):441-445.

103. Hamed LM, Tse DT, Glaser JS, Byrne SF, Schatz NJ. Neuroimaging of the optic nerve after fenestration for management of pseudotumor cerebri. Arch Ophthalmol. 1992;110(5):636-639.

104. Brodsky MC, Rettele GA. Protracted postsurgical blindness with visual recovery following optic nerve sheath fenestration. Arch Ophthalmol. 1998;116(1):107-109.

105. Radvany MG, Solomon D, Nijjar S, et al. Visual and neurological outcomes following endovascular stenting for pseudotumor cerebri associated with transverse sinus stenosis. $J$ Neuroophthalmology. 2013;33(2):117-122.

106. Fields JD, Javedani PP, Falardeau J, et al. Dural venous sinus angioplasty and stenting for the treatment of idiopathic intracranial hypertension. J Neurointerv Surg. 2013;5(1):62-68.

107. Kumpe DA, Bennett JL, Seinfeld J, Pelak VS, Chawla A, Tierney M. Dural sinus stent placement for idiopathic intracranial hypertension. J Neurosurg. 2012;116(3):538-548.

Journal of Pain Research

\section{Publish your work in this journal}

The Journal of Pain Research is an international, peer-reviewed, open access, online journal that welcomes laboratory and clinical findings in the fields of pain research and the prevention and management of pain. Original research, reviews, symposium reports, hypothesis formation and commentaries are all considered for publication.
108. Bussière M, Falero R, Nicolle D, Proulx A, Patel V, Pelz D. Unilateral transverse sinus stenting of patients with idiopathic intracranial hypertension. Am J Neuroradiol. 2010;31(4):645-650.

109. Ahmed RM, Zmudzki F, Parker GD, Owler BK, Halmagyi GM. Transverse sinus stenting for pseudotumor cerebri: a cost comparison with CSF shunting. AJNR Am J Neuroradiol. 2014;35(5):952-958.

110. Ducruet AF, Crowley RW, McDougall CG, Albuquerque FC. Long-term patency of venous sinus stents for idiopathic intracranial hypertension. J Neurointerv Surg. 2014;6(3):238-242.

111. Albuquerque FC, Dashti SR, Hu YC, et al. Intracranial venous sinus stenting for benign intracranial hypertension: clinical indications, technique, and preliminary results. World Neurosurg. 2011; 75(5-6):648-652; discussion 592-595.

112. Ahmed RM, Wilkinson M, Parker GD, et al. Transverse sinus stenting for idiopathic intracranial hypertension: a review of 52 patients and of model predictions. AJNR Am J Neuroradiol. 2011;32(8): 1408-1414.

113. Donnet A, Metellus P, Levrier O, et al. Endovascular treatment of idiopathic intracranial hypertension: clinical and radiologic outcome of 10 consecutive patients. Neurology. 2008;70(8):641-647.

114. Higgins JNP, Cousins C, Owler BK, Sarkies N, Pickard JD. Idiopathic intracranial hypertension: 12 cases treated by venous sinus stenting. J Neurol Neurosurg Psychiatry. 2003;74(12):1662-1666.

115. Altıoka-Uzun G, Tüzün E, Ekizoğlu E, et al. Oligoclonal bands and increased cytokine levels in idiopathic intracranial hypertension. Cephalalgia. Epub 2015 Feb 19.

116. Edwards LJ, Sharrack B, Ismail A, et al. Increased levels of interleukins 2 and 17 in the cerebrospinal fluid of patients with idiopathic intracranial hypertension. Am J Clin Exp Immunol. 2013;2(3):234-244.

117. Dhungana S, Sharrack B, Woodroofe N. Cytokines and chemokines in idiopathic intracranial hypertension. Headache. 2009;49(2): 282-285.

118. Brettschneider J, Hartmann N, Lehmensiek V, Mogel H, Ludolph AC, Tumani H. Cerebrospinal fluid markers of idiopathic intracranial hypertension: is the renin-angiotensinogen system involved? Cephalalgia. 2011;31(1):116-121.

119. Huang LC, Winter TW, Herro AM, et al. Ventriculoperitoneal shunt as a treatment of visual loss in idiopathic intracranial hypertension. J Neuroophthalmol. 2014;34(3):223-228.

120. Ushewokunze S, Haja Mydin HN, Prasad R, Mendelow AD. Lumbar subcutaneous shunt: a novel technique for therapeutic decision making in normal pressure hydrocephalus (NPH) and benign intracranial hypertension (BIH). Br J Neurosurg. 2008;22(5):678-681.

121. Sencer A, Akcakaya MO, Basaran B, et al. Unilateral endoscopic optic nerve decompression for idiopathic intracranial hypertension: a series of 10 patients. World Neurosurg. 2014;82(5):745-750.

122. Nithyanandam S, Manayath GJ, Battu RR. Optic nerve sheath decompression for visual loss in intracranial hypertension: report from a tertiary care center in South India. Indian J Ophthalmol. 2008;56(2): $115-120$

123. Goh KY, Schatz NJ, Glaser JS. Optic nerve sheath fenestration for pseudotumor cerebri. J Neuroophthalmol. 1997;17(2):86-91.

124. Sergott RC, Savino PJ, Bosley TM. Modified optic nerve sheath decompression provides long-term visual improvement for pseudotumor cerebri. Arch Ophthalmol. 1988;106(10):1384-1390.

125. Knight RS, Fielder AR, Firth JL. Benign intracranial hypertension: visual loss and optic nerve sheath fenestration. $J$ Neurol Neurosurg Psychiatry. 1986;49(3):243-250.

\section{Dovepress}

The manuscript management system is completely online and includes a very quick and fair peer-review system, which is all easy to use. Visit http://www.dovepress.com/testimonials.php to read real quotes from published authors. 